\title{
Energy tourism or spiritual tourism case study: Takht-e Soleiman, Iran
}

\author{
S. Sanaye Goldouz ${ }^{1} \&$ S. A. Ataie ${ }^{2}$ \\ ${ }^{I}$ Department of Environment, Tehran University and Iranian Association \\ for Environmental Assessment (IAEA), Iran \\ ${ }^{2}$ Ashti Ba Zamin (Making Peace with the Earth, an NGO), Iran
}

\begin{abstract}
One of the purposes of tourism is to perceive the vital energy of the Earth. The Earth Chakras or the sacred sites are the locations where this energy can be experienced. Takht-e Soleiman (also spelt Soleyman) is one of these sacred sites in Iran. It is an archaeological site located 45 kilometers northeast of the city of Takab in the province of West Azarbaijan. It is a heritage site left from the Sassanid era (226-650 AD). Takht-e Soleiman was not only registered by UNESCO in 2003 as a world heritage site, but also introduced as a sacred site in 1967. Since 2004, many tourists have visited the site each year to perceive the energy. These tourists are referred to as the Energy tourists (also called Spiritual or Vital Energy tourists). In this research, perception of the energy by the Energy tourists visiting the sacred site Takht-e Soleiman was surveyed. The survey was conducted in the summer of 2008. The focus group comprised 200 energy tourists. A questionnaire was presented and 140 tourists participated. After statistical analysis, 111 participants had sensed the energy in Takht-e Soleiman. The tourists explained their perception of the energy in detail. This kind of tourist is a peaceable one and travels to seek healing and to protect the Earth. The development of this kind of tourism will lead to worldwide peace and sodality, besides improving the environmental approach.
\end{abstract}

Keywords: Takht-e Soleiman, Takht-e Soleyman, Earth chakras, the sacred sites, tourism, energy tourism, vital energy tourism, spiritual tourism, subtle energy, vital energy. 


\section{Introduction}

Tourism as a process is deeply connected with the human body and spirit. Tourists travel for many reasons. Due to these reasons, many kinds of tourism have been developed in the world. Ecotourism, Geo tourism, Medical tourism, Religious tourism and Heritage tourism, to name a few [1].

Ecotourism (also known as ecological tourism) appeals to ecologically and socially conscious individuals. Generally speaking, it focuses on volunteering, personal growth and environmental responsibility. It typically involves visiting destinations where flora, fauna, and cultural heritage are the primary attractions. One of the goals of ecotourism is to offer tourists an insight into the impact of human beings on the environment and foster a greater appreciation of our natural habitats. Responsible ecotourism includes programs that minimize the negative impacts of conventional tourism on the environment and enhances the cultural integrity of local people. Therefore, in addition to evaluating environmental and cultural factors, an integral part of ecotourism is the promotion of recycling, energy efficiency, water conservation and creation of economic opportunities for local communities (Honey [2]).

Ecotourism is responsible traveling to fragile, pristine and usually protected areas that strives to be low impact and often on a small scale. It purports to educate the traveler, provide funds for conservation, directly benefit the economic development and political empowerment of local communities, and foster respect for multiculturalism and human rights. Ecotourism is held as important by those who participate in it so that future generations may experience aspects of the environment relatively untouched by human intervention (Randall [3]).

Heritage tourism (Cultural heritage tourism) is a branch of tourism oriented towards the cultural heritage of the location where tourism is occurring. It involves visiting historical or industrial sites that may include old canals, railways, battlegrounds, etc. The overall purpose is to gain an appreciation of the past. Heritage and the arts have long contributed to the appeal of tourist destinations. However, in recent years 'culture' has been rediscovered as an important marketing tool to attract those travelers with a special interest in heritage and arts. Cultural heritage tourism is the fastest growing segment of the tourism industry because there is a trend toward an increase in specialization among tourists. This trend is evident in the rise in the number of tourists who seek adventure, culture, history, archaeology and interaction with local people (Weiler and Hall [4]).

Medical tourism (also called medical travel, health tourism or global healthcare) is a term initially coined by travel agencies and the mass media to describe the rapidly growing practice of traveling across international borders to obtain healthcare. It also refers pejoratively to the practice of healthcare providers traveling internationally to deliver healthcare (Shaywitz and Ausiello [5] and Bezruchka [6]).

The concept of medical tourism is not a new one. The first recorded instance of medical tourism dates back thousands of years when Greek pilgrims traveled 
from all over the Mediterranean to a small territory in the Saronic Gulf called Epidauria. This territory was the sanctuary of the healing god Asklepios. Epidauria became the original travel destination for medical tourism. Spa towns and sanitariums may be considered an early form of medical tourism. In eighteenth century England, for example, patients visited spas because they were places with supposedly health-giving mineral waters, treating diseases from gout to liver disorders and bronchitis (Gahlinger [7]).

Religious tourism, also commonly referred to as faith tourism, is a form of tourism, whereby people of faith travel individually or in groups for pilgrimage, missionary, leisure or fellowship purposes (Jordan [8]).

Geotourism is "best practice" tourism that sustains, or even enhances, the geographical character of a place, such as its culture, environment, heritage, natural attractions and the well-being of its residents. The concept was introduced publicly in a 2002 report by the Travel Industry Association of America (as of 2009 this organization adapted its name to U.S. Travel Association) and the National Geographic Traveler magazine. Like ecotourism, geotourism promotes a virtuous circle whereby tourism revenues provide a local incentive to protect what tourists are coming to see, but extends the principle beyond nature and ecology to incorporate all characteristics that contribute to a general sense of the place, such as historic structures, way of life and traditional culture, landscapes, cuisine, arts, as well as local flora and fauna. Geotourism incorporates sustainability principles (Weiler and Hall [9]).

The environmental conditions and natural attractions of a destination always add values to the travel goal. Natural attractions are the geographic or geological features that attract the tourist [10].

There are many places on the Earth with natural attractions for healing, relaxing and awareness of people which have resulted in coining the phrases "sacred sites" and "the Earth or planetary chakras" by Robert Coon in 1967. These places also have the archeological, religious and cultural attractions. The Earth chakras have the vital energy that enhances physical, mental, emotional and spiritual health. The earth chakras are the vortices that circulate the energy around the planet. These chakras were determined in 1967 by Coon [11].

The idea of the earth chakras have been derived from believing in Gaia Hypothesis. The Gaia Hypothesis suggests that our planet functions as a single organism that maintains conditions necessary for its survival. Formulated by James Lovelock in the mid-1960s and published in The Gaia Hypothesis in 1979, this controversial idea has spawned several interesting notions and many new areas of research. While this hypothesis is by no means substantiated, it provides many useful lessons about the interaction of physical, chemical, geological and biological processes on Earth. The idea of the Earth acting as a single system as put forth in the Gaia Hypothesis has stimulated a new awareness of the connectedness of all things on our planet and the impact that man has on global process [12].

This hypothesis also developed the idea that the Earth is alive and as a super existence has a nervous system. The web of life on Earth both creates and is affected by electrical currents on the Earth's surface and in the atmosphere. The 
soil with its electrically conducting gases, metals, semiconducting mineral crystals, water-soaked organic matter, and electrolytes offers an excellent medium for producing and maintaining electrical currents. The mineralogy of the start below the surfaces conducts in kind. Moving water, such as waterfalls, rain and breaking waves, also produces charges. Charged particles (ions) are drawn to the ground (planetary boundary layer) and high concentrations increase the intensity of earth-currents (electrode effect). The idea explains the Earth is a selfaware consciousness with a living body, mind and spirit (Tyberonn [13]).

The Earth is a living being, with its own creative, evolutionary will, and with its own methods of enacting its purpose. The electromagnetic characteristic of the Earth establishes a system of energy around it. The greatest concentrations of energy encoded with information emanate from major Earth Chakras. The study of Earth Chakras is more akin to acupuncture, in that we are exploring the more subtle energy structures of the Earth. Earth Chakras are like bodily organs that are vital to the health of the world, and to all living beings dependent upon the various environments provided by the world. Each chakra serves a different function, which is twofold: to maintain the overall global health and to transmit and receive energy encoded with information. There is one major Earth Chakra on each continent, with the exception of Antarctica. The entire planetary structure contains 156 sites, which create 52 vortices or chakras. These 156 sites are called sacred sites and lie on the intersection points of meridians such as Glastonbury in England, Mt. Kailas in Tibet, Lima in Peru, Niagara Falls between the United States and Canada, Uluru in Australia and so on. Energy and information can be sent from any site and arrive at any other site on the Earth. This energy has a frequency that makes the physical and spiritual connection of life on the Earth (Coon [14]). According to this, there are three sacred sites in Iran: Takht-e Soleiman, Mt. Damavand and Kuh-e Malek Siah. The case study of this research was conducted in the sacred site of Takht-e Soleiman (Soleyman).

\section{Takht-e Soleiman and energy tourism}

Takht-e Soleiman is an ancient archeological site located 45 kilometers northeast of the modern town of Takab in the province of West Azarbaijan, Iran. Takht-e Soleiman is literally translated as the Throne of Solomon. King Solomon is the subject of many legends in the region in history. Sometime in the first millennium BCE people began to settle the area, and during the Achaemenian dynasty it started to become a center of Zoroastrianism [15]. It is the heritage left from the Sassanid era (226-650 AD) and the home of one of the three famous Sassanid fire temples. It is also the place where the kings of the Sassanid dynasty were crowned. Although the site is now severely deteriorated, it remains an exciting example of early regional architecture. The historic monument in Takhte Soleiman has been built around a lake in the form of an oval structure and is enclosed by a stone wall. The holy lake is absolutely eye-catching with its changing colors. The ancient site is most known for its Sassanid monuments such as Azargoshnasb Fire Temple, Anahita Temple, Hadaya (Gifts) Museum, Zendan (Jail) Mountain and Belgheis Castle Homayouni [16]. Takht-e Soleiman 


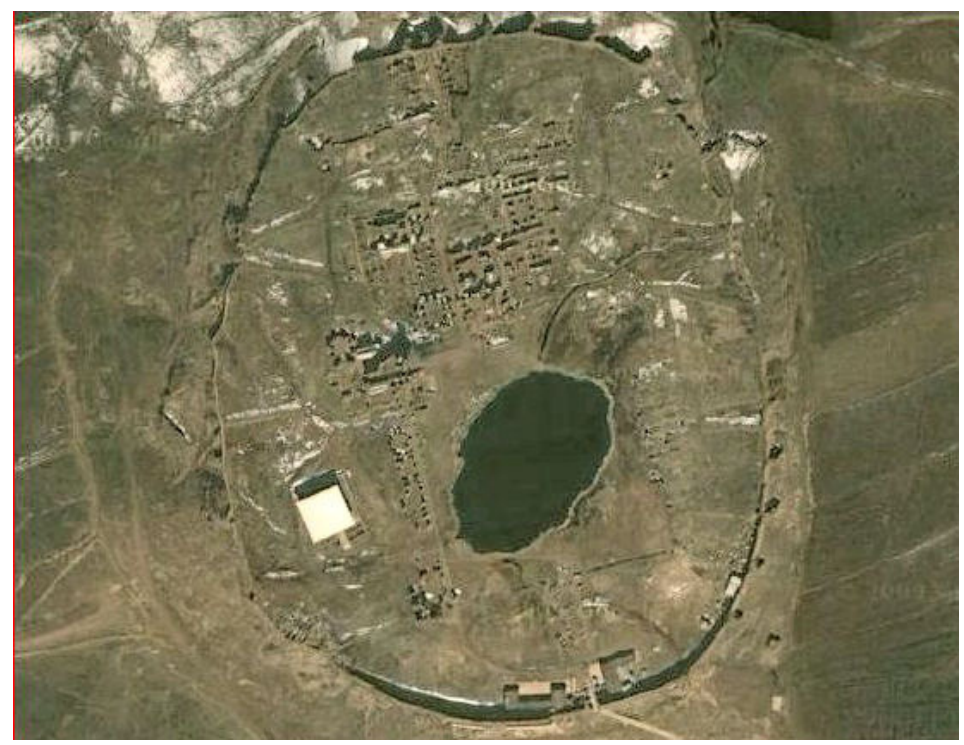

Figure 1: An aerial photograph of Takht-e Soleiman [17].

is an important archaeological site in Iran that was not only registered by UNESCO in 2003 as a world heritage but also introduced as a sacred site in 1967. The bird's-eye view of Takht-e Soleiman is shown in fig. 1.

In 2004, an environmental movement was formed in Iran by Sanaz Sanaye Goldouz and Sayed Abbas Ataie. They together with many other environmentalists who believed in subtle and vital energy of the Earth went to Takht-e Soleiman [18]. That year, all the tourists, feeling great rapture, made a circle around the mesmerizing lake and prayed for peace. The purpose of the travel was Ecotourism, but with a twist. The Ecotourist respects the physical body of the Earth but the Energy tourist not only respects the physical body of the Earth but also respects the soul of it (Goldouz and Makhdoum [20]). This movement has flourished tourism in Takht-e Soleiman. Since 2004, many tourists have visited the site each year to perceive its energy. The tourists meditate, focus their attention within, release tension and relax, turn around the holy lake quietly, breathe deeply, promenade, interchange the energy, heal themselves and the world, experiment the metaphysical senses and respect and protect the environment and also pray for peace. The tourists feel the presence of God in the sky and on the Earth and everywhere. This type of tourist is called the Energy Tourist, the Vital Energy Tourist, the Subtle Energy Tourist or the Spiritual Tourist (Goldouz and Ataie [19]). The human circle around the lake and praying for peace are shown in figs. 2 and 3.

In this research, perceiving and absorption of the energy by the tourists in the sacred site Takht-e Soleiman was surveyed. 


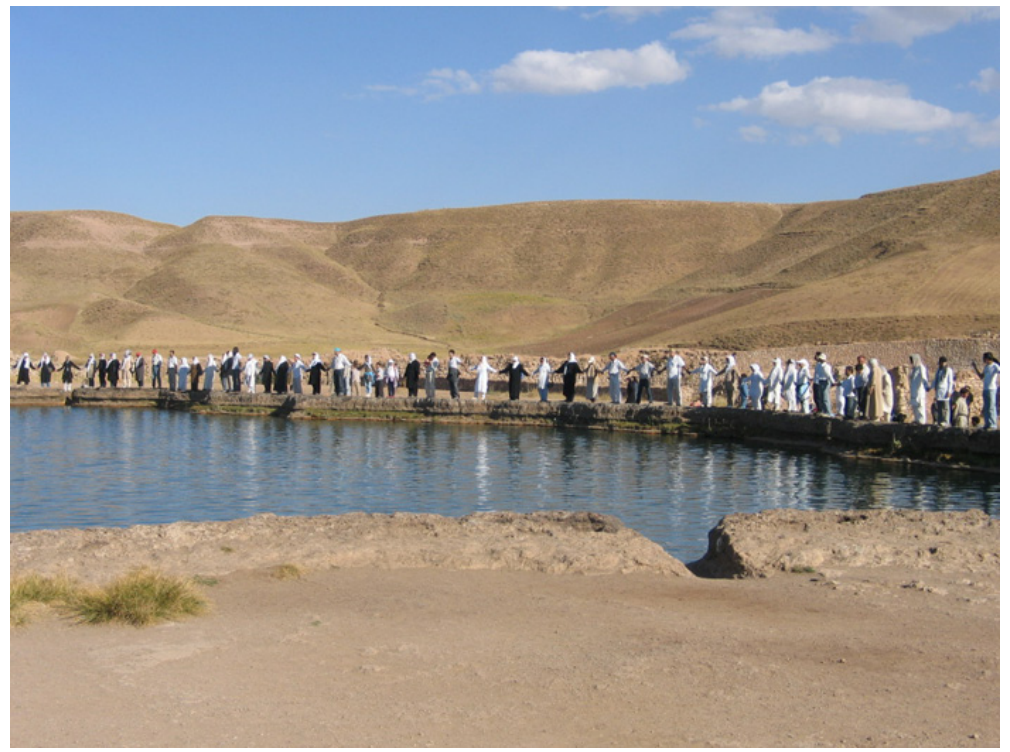

Figure 2: $\quad$ Praying for peace [21].

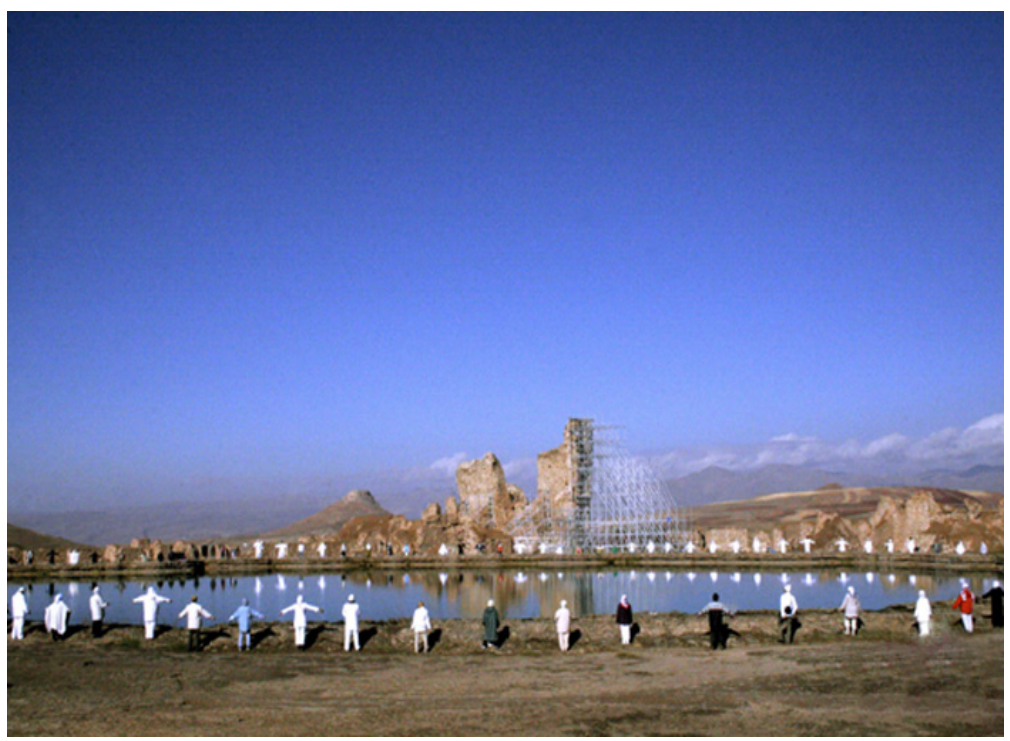

Figure 3: $\quad$ The circle of peace [22]. 


\section{Data and methods}

After 4 years of traveling to Takht-e Soleiman, via repeatable and experimental observations, interviews and field studies, many tourists confirmed the existence of the energy in Takht-e Soleiman. Having a questionnaire was determined as the method for the survey part of the research.

The survey was conducted in the summer of 2008. The focus group comprised 200 energy tourists. One hundred and forty five questionnaires were distributed to them at random. The questionnaires were filled out by 140 people. Since the questionnaire was composed of multi-valued questions with ordinal scale, the sample size was estimated as follows Momeni and Ghayoumi [23]:

$$
n=\frac{N \times z^{2} \frac{\alpha}{2} \times p(1-p)}{\varepsilon^{2}(N-1)+z^{2} \frac{\alpha}{2} \times p(1-p)}
$$

In this formula, "N" is the population size, "p" is the probability of success, " $\alpha$ " is the error size and " $\epsilon "$ is the accuracy of estimation. The sample size was estimated as follows:

$$
\begin{gathered}
n=\frac{200 \times(1.96)^{2} \times 0.5(1-0.5)}{(0.05)^{2}(200-1)+(1.96)^{2} \times 0.5(1-0.5)} \\
=131.75 \approx 132
\end{gathered}
$$

According to $140>132$ responses received, the results were extensible to the population with a $95 \%$ confidence level.

The questionnaires were analyzed. The cross tab of the age group and the sex of responders are shown in Table 1.

The responders had various education levels, which were divided into 6 categories. Table 2 indicates the abundance of the education levels of responders.

Table 1: $\quad$ Cross tab of age and sex of responders.

\begin{tabular}{|l|c|c|c|}
\hline \multirow{2}{*}{ Age } & \multicolumn{2}{|c|}{ Sex } & \multirow{2}{*}{ Total } \\
\cline { 2 - 3 } & Male & Female & \\
\hline $10-15$ & 2 & 1 & 3 \\
\hline $16-25$ & 7 & 19 & 26 \\
\hline $26-45$ & 27 & 59 & 86 \\
\hline $46+$ & 4 & 21 & 25 \\
\hline Total & 40 & 100 & 140 \\
\hline
\end{tabular}


Table 2: $\quad$ The abundance of education levels.

\begin{tabular}{|l|c|c|}
\hline Education level & Number of people & Percentage \\
\hline Below secondary school diploma & 9 & 6.3 \\
Secondary school diploma & 32 & 22.8 \\
Bachelor & 74 & 52.8 \\
Master & 16 & 11.6 \\
Ph.D. & 2 & 1.6 \\
Professional Doctorate & 3 & 2.1 \\
\hline Subtotal & 136 & 97.2 \\
\hline No responded & 4 & 2.8 \\
\hline Total & 140 & 100 \\
\hline
\end{tabular}

Table 3: Contingency table of the purpose of travel and sensing the energy in Takht-e Soleiman.

\begin{tabular}{|c|c|c|c|c|c|c|}
\hline \multirow[b]{2}{*}{ The purpose of travel } & \multicolumn{4}{|c|}{ Sensing the energy } & \multirow[b]{2}{*}{ Total } & \multirow[b]{2}{*}{$\begin{array}{l}\text { Cumulative } \\
\text { Percentages }\end{array}$} \\
\hline & 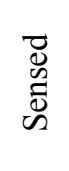 & 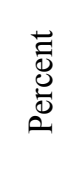 & 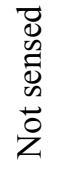 & 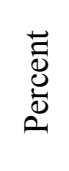 & & \\
\hline Curiousness & 24 & 17.1 & 12 & 8.6 & 36 & 25.7 \\
\hline Perceiving the energy & 87 & 62.2 & 17 & 12.1 & 104 & 74.3 \\
\hline Total & 111 & 79.3 & 29 & 20.7 & 140 & 100 \\
\hline
\end{tabular}

After collection and analysis of the data in Excel and SPSS, the contingency table was provided. The fisher's test was used for analyzing the table. After statistical analysis, with $\mathrm{p}$-value $=0.030 \leq 0.05$, a total of 111 tourists had sensed the energy in Takht-e Soleiman. The purpose of travel and sensing the energy are shown in Table 3.

The purpose of travel of 36 people was curiousness and the purpose of the rest (104 people) was to perceive the energy.

\section{Findings and discussion}

In general, there are two types of tourists in Takht-e Soleiman. The foreign tourists travel to this site because it is a registered archaeological site and it is also a very valuable tourist attraction in Iran. Iranian tourists are the locals and others from near and far cities. The second type is different with various goals, such as Ecotourist, Geotourist for natural attractions, Medical tourist for healthgiving mineral water, Heritage tourist, Religious tourist (Zoroastrians) and Conventional tourist. The latest goal is that of the energy tourists or spiritual tourists who have visited this site since 2004 in order to perceive the vital and subtle energy. In this research 111 people both male and female with proper 
education levels confirmed the existence of energy in Takht-e Soleiman. Experiencing this kind of energy was explained as: real love, spiritual appetence, fascination, astonishment, rapture, peacefulness, awareness, high energy, joy, feeling healthy, lightness, feeling at home, happiness, relieving stress, feeling the presence of God, complete satisfaction, increasing the hope for life, admiring nature, beauty, indescribable feelings and perceptions, metaphysical experiences, new experience, uncaused emotions, unknown fear and so forth. Most of the tourists were full of energy when returning home. They stated that their approach to life had changed. They also said that Takht-e Soleiman was very different from other natural attractions in Iran. For example, there is a very beautiful lake in the great volcanic mountain of Sabalan, but the eye-catching lake of Takht-e Soleiman is much more wonderful and amazing. They enjoyed being dazed by the lake for a long time as though it was hypnotizing them.

This kind of tourist tries to protect the site due to a feeling of ownership and dependence on it. The tourists believe that the Earth is alive and has a soul and a purpose for living. They feel the existence of the Earth in this site. Therefore, they just cannot damage it.

This kind of tourist is very similar to the Ecotourist who intends to protect the environment and improve on the conventional tourist's approach to Takht-e Soleiman whereby reducing the damage to the environment, it has some similarities to the other kinds of tourists that visit Takht-e Soleiman. Energy tourists or Spiritual tourists travel to Takht-Soleiman to heal themselves and the world. So, they have the medical purpose like Medical tourists and also the natural attractions attract them like Geotourist. They visit the site to feel closer to God in a similar way to religious tourists. Additionally, as Takht-e Soleiman is a heritage site, compliance with the laws governing such sites applies to the energy tourists as well.

The Energy tourist's style shows content: they dress in white to attract the energy better and also white is the color of peace, have vegetarian diets, try to remain quiet, meditate and focus within, meditate in a group, walk around the lake 7 times (with the intent to honor the seven principal chakras) and make a circle of peace surrounding the lake. This kind of tourist travels with simplicity, needs simple facilities and special tour leaders that are trained for this purpose.

Religion or cultural background of the tourist would not make a difference. The goal of the Energy tourist and the Spiritual tourist is the achievement of unification of humanity in the world for peace and for protection of the Earth. So, race, nationality, culture, religion and so on are not important. The people of each country where the earth chakra belongs should serve as the protectors and guardians of it. These heritage and valuable sites belong to all the people the world over. The development of this kind of tourism will contribute to the worldwide peace and sodality and improve the environmental approach.

\section{References}

[1] World Tourism Organization, www.unwto.org/index.php 
[2] Honey, M. Ecotourism and Sustainable Development: Who Owns Paradise? Washington, DC: Island Press, Second Edition, 33 pp., 2008.

[3] Randall, A. Resource economics, New York, USA: John Wiley and Sons. Second Edition, 113 pp., 1987.

[4] Weiler, B. \& Hall, C. M. Specia - Interest Tourism, Belhaven pr. Pub., 224 pp., 1992.

[5] Shaywitz, D. A. \& Ausiello, D. A. Global Health: A Chance for Western Physicians to Give - and Receive, The American Journal of Medicine, No. 113, pp. 354-357, 2002.

[6] Bezruchka, S. Medical Tourism as Medical Harm to the Third World: Why? For Whom? Wilderness and Environmental Medicine, No. 11, pp. 77-78, 2000.

[7] Gahlinger, P. M. The Medical Tourism Travel Guide: Your Complete Reference to Top-Quality, Low-Cost Dental, Cosmetic, Medical Care \& Surgery Overseas, Sunrise River Press, pp. 23-34, 2008.

[8] Jordan, M. Seeking Answers with Field Trips in Faith, Washington Post Foreign Service, June 25, 2007.

[9] Weiler, B. \& Hall, C. M. The Geotourism Study from the Travel Industry Association of America and National Geographic Traveler, Business Services Industry, June 3, 2002.

[10] Tourism dictionary Online, www.tourismdictionary.com

[11] Coon, R. The Earth is Alive, 2005. www. worldalchemy.bravehost.com

[12] Gaia Hypothesis, www.oceansonline.com/gaiho.htm

[13] Tyberonn. Defining GAIA: An Earth Energy Glossary, The Vital Vastness, 2002. www.earth-keeper.com/defininggaiaarticle.shtml

[14] Coon, R. Earth Chakras. Robert Coon Pub., 293 pp., 2009.

[15] British Institute of Persian Studies, Archaeological sites, www.bips.ac.uk/ sites/Takht-e-Soleyman

[16] Homayouni, B. Here is Takht-e Soleyman. Persian Journal, Second No. pp. 10-13, 2006.

[17] Photography by Google Earth, 2009.

[18] The Heritage Site "Takht-e Soleyman", The History of Tourism in Takht-e Soleiman, Personal communication, 2005.

[19] Sanaye Goldouz, S. \& Ataie, S. A. The Vital Jewel, Forouzesh Journal, New Vol., No. 4, pp. 109-110, 2009.

[20] Sanaye Goldouz, S. \& Makhdoum, M. Appraising Psychosocial Carrying Capacity of Ecotourism in Sacred and Energetic Sites (Case; Takht-e Soleiman, Throne of Soloman, Iran), Journal of Environmental Studies, Iran, Vol. 35, No. 51, pp. 37-45, 2009.

[21] Ashti ba zamin (Ngo) Web Sites, Photography in 2004, www.yinyangreiki.org and www.ashtibazamin.org

[22] Ashti ba zamin (Ngo) Web Sites, Photography in 2006, www.yinyangreiki.org and www.ashtibazamin.org

[23] Momeni, M. \& Ghayoumi, A. Statistical Analysis with Spss, New Book Pub. 302 pp., 2007. 